\title{
On Technostress and Emotion: A Narrative Approach
}

\author{
Christopher B. Califf \\ Western Washington University \\ califfc@wwu.edu
}

\begin{abstract}
Emotion in the context of technostress has been treated by IS researchers as highly general and vague. Little is therefore known about how individuals experience specific emotions when undergoing technostress. This paper is a first step towards understanding how to uncover the relationship between technostress (more specifically technostressors) and emotion through a narrative approach. Drawing on The Holistic Technostress Model as a theoretical foundation, and guided by research on psychological stress and emotion, the paper advocates for using emotion narratives to create stories about how emotions are experienced during stressful situations involving technology. The paper illustrates how six hypothetical emotion narratives related to technostress: anger, envy, relief, hope, happiness-joy, and pride. The paper also discusses how IS researchers can use emotion narratives in a variety of empirical studies, such as in survey and qualitative research designs and mixed-methods approaches.
\end{abstract}

\section{Introduction}

"Where there is stress there are also emotions" [1, p. 35]. Over the last few decades, technology-related stress has been studied in the information systems (IS) discipline in a variety of ways. For example, in the 1980s, IS researchers studied stress experienced by managers or employees who work for technology companies [2, 3]. In the 2000s, the technological component in technology-related stress was emphasized by investigating how several technologyrelated stressors, or techno-stressors, negatively impacted individual and organizational outcomes [4, 5]. This shift towards illuminating the technology in stress research was the first step towards studying the concept of technostress, which focused on investigating how technology may induce deleterious individual and organizational outcomes [5]. Underlying this shift is the assumption that technostress is automatically negative, and that the techno-stressors are detrimental to an individual and an organization.

\author{
Mark C. Springer \\ Western Washington University \\ springer@wwu.edu
}

More recently, there has been another shift in technostress research - one that addresses the negative and positive aspects of technostress and reframes technostress as an ongoing process $[6,7,8]$. This shift depicts technostress as an overarching process that includes several components, such as environmental conditions that materialize into positive and negative techno-stressors, psychological-emotional responses, and outcomes [7]. The technostress process involves two important sub-processes: the techno-eustress process, which is associated with "good" or "motivating" stress related to technology, and the techno-distress process, which is associated with "bad" or "destructive" stress related to technology [7, 8]. This view of technostress was recently theorized and empirically validated in a mixed-methods design [7]. In the paper, the authors introduced and validated The Holistic Technostress Process Model [7].

The Holistic Technostress Process Model underscores the importance of an individual's ability to appraise a neutral techno-stressor as a challenge techno-stressor or a hindrance techno-stressor. A challenge techno-stressor is a techno-stressor that is appraised as helping to accomplish tasks that require technology; a hindrance techno-stressor is a technostressor that is appraised as a barrier to accomplishing tasks that require technology [7]. The model also highlights the relationship between challenge and hindrance techno-stressors and an individual's emotional psychological response. The authors argue that the emotional psychological response establishes how an individual will react to a techno-stressor and guides the formation of important individual and/or organizational outcomes, such as being satisfied (or dissatisfied) with one's job or quitting.

In this sense, Califf et al. [7] argued that an individual's emotional reaction provides valuable insight into revealing not only how a techno-stressor is experienced, but also how the emotional reaction may shape important outcomes. However, the authors treat the emotional psychological response as a general (and seemingly stable) psychological state, and not as a specific emotion, such as anger, hope, joy, and so on. They also do not provide much guidance on how to study specific emotions in the context of technostress. To elaborate, the authors provided several qualitative 
examples about nurses undergoing technostress. In one example, several nurses discuss how they appraise the technology they use to deliver patient care as being highly useful, which the authors conceptualized as a challenge techno-stressor. The authors then tested empirically the relationship between technology's usefulness, a well-known psychological construct in IS research, and a positive psychological-emotional state, measured by general terms for positive emotions. The two constructs were found to be significantly related; that is, the more useful nurses found the technology, the higher their positive psychological-emotional state [7].

While researchers and healthcare managers need to understand that nurses may experience a positive emotional state related to technology's usefulness, currently there is no guidance in IS research on how to recognize the specific positive emotion that nurses (and other individuals) may feel, and how that emotion is related to technology's usefulness (or other technostressors). The nurses for example could be feeling happiness, joy, or hope (or other emotions) about technology being useful, which is relevant information for researchers and managers [1]. In this sense, though a solid theoretical foundation of technostress exists that has been empirically supported, there is little information on how to investigate and recognize the role specific emotions play in the technostress process. Thus, an opportunity currently exists to expand on the role specific emotions may play in the context of technostress.

This paper aims to fill this gap by introducing and discussing a novel approach to investigating specific emotions in the context of technostress. The approach is hereafter referred to as the narrative approach to technostress and emotion. This approach answers the call of well-known stress researcher Richard Lazarus to use emotion narratives in stress research [1]. Guided by Lazarus's ideas [1] and using The Holistic Technostress Process Model as the foundation of technostress, this paper provides IS researchers with a way to recognize and reveal how individuals articulate the role specific emotions play in technostress, and, specifically, as related to a techno-stressor. In this way, the paper follows the lead of Lazarus [1], who emphasizes that: "knowing the emotion being experienced provides a ready understanding of how it was brought about" (p. 34). Understanding how individuals experience an emotion when undergoing technostress can therefore provide detailed insight into (1) how a techno-stressor may materialize, (2) how a techno-stressor was initially appraised, and (3) the relationship between a techno-stressor and specific emotions. IS researchers and managers can also use the narrative approach to technostress and emotion to obtain a richer understanding of the technostress process to anticipate how employees may react to certain technology-related stressors and how such a reaction may relate to important psychological and organizational outcomes (e.g., turnover intention, job satisfaction, actual turnover).

The narrative approach to technostress involves creating emotion narratives (also called emotion vignettes) that describe the emotional experiences of individuals undergoing technostress. An emotion narrative is defined as "a dramatic plot or story that describes the provocation of the emotion and its background, which helps define what made some action or lack of action when it is desired, provocative, and how it progressed and turned out" [9]. In this sense, an emotion narrative may offer the IS researcher insight into not only the emotional reaction itself, but how it may be related to a techno-stressor or an individual or organizational outcome.

The current paper illustrates six hypothetical emotion narrative prototypes that are meant to serve as examples of what an emotional experience may look like when an individual is experiencing technostress. Though hypothetical, the prototypes are loosely based on personal experience and field interviews conducted by the first author. The emotion narratives focus on the relationship between techno-stressors and specific emotions: anger, envy, relief, hope, happiness-joy, and pride. These six emotions are by no means an exhaustive list of emotions that may relate to an individual experiencing technostress; they are meant to provide the first step towards a narrative approach to technostress and emotion.

Overall, the paper offers the following contributions. First, the paper provides IS researchers with a new approach to revealing the connection between emotions and technostress. Second, the paper can help to contextualize the relationship between the individual and the technology and uncover the ideographic experience of the individual undergoing technostress; this is a step towards uncovering the "essence" of stress [10]. Third, the paper provides an important step towards advancing the literature on technostress and emotions. Fourth, the paper provides information about how IS researchers may use emotion narratives in research that involves surveys, mixed methods, and qualitative designs.

The paper is organized as follows: First, a discussion of stress, technostress, and emotions is offered. Next, examples of the narrative approach to technostress and emotion are presented. Finally, a discussion about how to use emotion narratives in IS research is provided. 


\section{Stress}

Stress has been described as "an ongoing process that involves individuals transacting with their environments" [10, p. 12]. When the individual transacts with their environment, they form a relationship with the environment, often referred to as the person-environment relationship $[10,11]$. The environment offers the individual something that aligns or does not align with their goals or values [12].

The process of stress has been unraveled through a holistic process model which involves appraisal, challenge and hindrance stressors, emotions, and outcomes [12]. The holistic process of stress starts with an individual appraising a neutral stressor as a challenge or a hindrance to accomplishing a task [13]. Through appraisal, the individual determines whether the stressor is a challenge stressor, which is associated with stressors "that tend to be appraised as promoting the accomplishment of job tasks and the personal development of the individual," or is a hindrance stressor, which is linked to stressors "in the workplace that tend to be appraised as barriers or obstacles to the accomplishment of job tasks and personal development of the individual" [12, p. 62]. The individual then, based on their appraisal, experiences positive or negative emotions. Challenge stressors are typically associated with positive emotions, such as hope or vigor, and subsequently positive workplace outcomes, such as high job satisfaction. Conversely, hindrance stressors are typically related to negative emotions, such as anger, and subsequent negative personal and workplace outcomes such as low job satisfaction [12].

\section{Technostress}

Technostress is often described as a "dark side" phenomenon and is regularly defined as "a modern disease of adaptation caused by an inability to cope with new computer technologies in a healthy manner" [14]. Therefore, in IS research, technostress is commonly associated with the negative side of stress, called techno-distress. Technostress research often involves investigating how five negative technostressors impact individual and organizational outcomes. Five commonly identified techno-stressors include techno-overload, techno-invasion, technocomplexity, techno-insecurity, and techno-uncertainty $[4,5]$.

Techno-overload occurs when technology forces individuals to work faster. Techno-invasion is associated with the blurring of work and home life due to technology. Techno-complexity is linked to users feeling that their technology skills are inadequate.
Techno-insecurity involves users feeling threatened about losing their job due to technology or to others with better technical knowledge. Techno-uncertainty is related to the constant changes and upgrades that occur due to technology [4, 5]. Recently, several studies have conceptualized and empirically validated technostress as a positive as well as a negative phenomenon, and, in doing so, reframed technostress as having a "bright side" and a "dark side" [6, 7, 8]. As mentioned briefly in the introduction, The Holistic Technostress Process Model developed and tested by Califf et al. [7] defines technostress as an ongoing, overarching process comprised of two subprocessesthe techno-eustress subprocess and the techno-distress subprocess. In this model, the overarching process of technostress begins with the individual interacting with their environment and experiencing neutral technology-related stressors called techno-stressors.

Once appraised, the neutral techno-stressors are considered by the individual as challenge or hindrance techno-stressors $[7,8]$. Challenge techno-stressors are defined as techno-stressors that individuals "tend to appraise as related to promoting task accomplishment" [7, p. 815]. Challenge techno-stressors have been conceptualized as the individual appraising technology as useful or appraising their organization as highly supportive of learning technical skills. Hindrance techno-stressors, on the other hand, are techno-stressors that individuals "tend to appraise as related to a barrier or obstacle to task accomplishment" [7, p. 815]; these could include the five negative techno-stressors previously mentioned. After appraising the techno-stressors as beneficial to or a barrier to task accomplishment, the individual experiences a positive or negative emotional psychological state, and subsequently a positive or negative individual or organizational outcome, respectively [7]. Positive emotions are typically related to challenge techno-stressors, while negative emotions are typically related to hindrance technostressors. Until now, however, an understanding of the relationship between a techno-stressor with a specific emotion, such as anger, hope, happiness, and joy, have been left out of technostress research.

\section{Emotion and emotion narratives}

Emotions are critical to understanding human behavior and are viewed by psychological stress researchers as critical to revealing the essence of stress [7]. This is often done so using emotion narratives. An emotion narrative is "a dramatic plot or story that describes the provocation of the emotion and its background, which helps define what made some action or lack of action when it is desired, provocative, 
and how it progressed and turned out" [9]. The narrative typically includes a story of a possible action that triggers an emotional psychological response and, in particular, a detailed description of a specific emotion related to the possible action [1].

Since this view of stress emphasizes contextual relations between potential or actual actions and emotions, it is important to understand the context in which the researcher is investigating these actions and emotions. The researcher, when understanding the situational relevancy of the individual, can craft narratives that act as a story that describes the actions and corresponding emotions; this enables a better understanding of the emotions. Doing so involves what is known as creating "prototypical emotion narratives" [1].

\section{Narrative prototypes}

For a narrative approach to technostress to be of any use, stories, or narrative prototypes, about stressful situations that involve technology must be created. These narratives, or vignettes, serve as examples for different emotions [1]. For example, if the IS researcher is studying how care providers experience technology-related stressors and the related positive and negative emotions associated with such stressors, the researcher may write one or more contextually relevant narratives that illustrate potential techno-stressors and corresponding emotions. Before crafting the narratives, the researcher may first interview several nurses to understand how they use technology for work and ask them to describe stressful situations involving technology and to elaborate on the specific emotions they feel as related to the stressful situation.

Consider, for example, a narrative about technology-related anger. Anger may be a common emotion experienced by a care provider if technology crashes, freezes, and/or is generally unreliable. The researcher could write one or more narrative prototypes involving anger about the computer crashing. Of course, when used in an investigatory setting, the researcher can craft more contextually relevant narratives for each emotion as related to specific technology-related stressful situations. This is because each stressful situation differs and therefore so does the corresponding emotional relationship to each situation. Lazarus [1] suggests that before creating emotion narratives and using them in empirical research, the research must recognize that emotions themselves have several types. For example, anxiety has different kinds, such as anticipatory anxiety, guilt anxiety, and shame anxiety. The researcher must therefore be well-versed in the type of emotion they are investigating before crafting the narratives.

\section{Examples of potential narrative prototypes for technology-related emotions}

In this section, we illustrate six hypothetical emotion narratives related to stressful situations involving technology. The narratives, though hypothetical, are somewhat based on the field and personal experience of the first author.

Before we begin, we must note that each emotion has one or more core relational themes [1]. We therefore first briefly discuss the theme(s) related to each emotion and then reveal the hypothetical narrative of the emotion involving stressful situations related to technology (Table 1). The six emotions presented in this section are categorized as follows. The first two - anger and envy - are categorized as "nasty" and negative emotions; the third and fourth-relief and hope-can be classified as positive emotions that come from adverse conditions; the last two-happiness and pride-are positive emotions associated with favorable life conditions [1].

\subsection{Technology-related anger}

Anger depends on the individual's "goal of preserving or enhancing the self- or social-esteem" [1, p. 217]. Anger, therefore, occurs when the individual encounters a threat or harm to their self- or socialesteem. For anger to occur, the individual must consider their self-esteem and/or social-esteem harmed, impaired, or threatened, and must also place blame on themself and/or another person or object. The relational theme for anger therefore involves two key concepts: (1) harm and (2) blame.

Below is an example narrative of outward anger experienced in the context of a newly employed assistant professor teaching an introductory course. The professor wants his students to take him seriously and respect him as an academic. In the middle of his first two lessons, the classroom computer freezes multiple times. The professor appraises this as a threat to his social esteem (i.e., the students and colleagues may perceive him as an incompetent teacher). The professor subsequently blames the out-of-date computer and the university's help desk staff. The professor, therefore, experiences outward anger related to the unreliability of the classroom technology and the perceived ineffectiveness of the help desk staff. In IS research, the unreliability of technology and unsupportive help desk staff have been empirically validated as hindrance techno-stressors 


\begin{tabular}{|c|c|c|}
\hline \multicolumn{3}{|c|}{ Table 1. Technology-related Emotions, Definitions, and Narratives } \\
\hline $\begin{array}{c}\text { Technology- } \\
\text { Related Emotion }\end{array}$ & Definition and Example & Example narrative \\
\hline Anger & $\begin{array}{l}\text { An individual perceives that their self- } \\
\text { esteem or social esteem is being threatened } \\
\text { or harmed, and the individual places blame } \\
\text { on themself and/or others. }\end{array}$ & $\begin{array}{l}\text { An individual may feel a threat to self- } \\
\text { esteem due to the unreliability of the } \\
\text { technology and/or perceived incompetence } \\
\text { of the IT help desk staff. }\end{array}$ \\
\hline Envy & $\begin{array}{l}\text { An individual wanting what someone else } \\
\text { has and feeling as though they have been } \\
\text { cheated or deprived by comparing themself } \\
\text { to others in an unfavorable way. The } \\
\text { individual rationalizes or denies that they } \\
\text { are deprived. }\end{array}$ & $\begin{array}{l}\text { An individual feels inadequate in their } \\
\text { technology skills and compares themself to } \\
\text { more technologically competent employees. }\end{array}$ \\
\hline Relief & $\begin{array}{l}\text { An individual has a positive emotional } \\
\text { experience related to an unfavorable } \\
\text { condition. They experience a threat about a } \\
\text { given situation, and when the threat } \\
\text { subsides, they experience relief. }\end{array}$ & $\begin{array}{l}\text { An individual has previous experience with } \\
\text { unreliable technology or perceived } \\
\text { incompetent IT help staff. The individual } \\
\text { therefore dreads using the technology in a } \\
\text { critical situation. The individual however } \\
\text { does not experience any issues and is } \\
\text { therefore relieved. }\end{array}$ \\
\hline Hope & $\begin{array}{l}\text { Concerned with a desire for an unfavorable } \\
\text { situation to subside in the future. Hope is } \\
\text { related to an outcome that has not yet } \\
\text { occurred and is therefore considered an } \\
\text { "anticipatory emotion." }\end{array}$ & $\begin{array}{l}\text { An individual is frustrated with a recent } \\
\text { implementation of new software and feels } \\
\text { that they have inadequate technology skills. } \\
\text { The individual ultimately knows that the } \\
\text { shift to the new technology will be good for } \\
\text { the organization in the long run. }\end{array}$ \\
\hline Happiness-joy & $\begin{array}{l}\text { Happiness is a long-term calming feeling of } \\
\text { comfort and reassurance; joy is a relatively } \\
\text { short-term feeling, often lasting minutes, } \\
\text { hours, or perhaps days related to recent } \\
\text { events. The two are considered together to } \\
\text { decipher the true meaning of happiness or } \\
\text { joy. }\end{array}$ & $\begin{array}{l}\text { An individual feels elated about mastering } \\
\text { certain features of newly implemented } \\
\text { software, but is overall unhappy about } \\
\text { relying on technology to do their job. }\end{array}$ \\
\hline Pride & $\begin{array}{l}\text { Pride is defined as "enhancing one's self or } \\
\text { ego identity by taking credit for a valued } \\
\text { object or achievement either our own or that } \\
\text { of someone or group with whom we } \\
\text { identify" [1, p. 250]. }\end{array}$ & $\begin{array}{l}\text { An individual overcomes their feelings } \\
\text { about learning a complex technology and is } \\
\text { recognized by their peers or superiors for the } \\
\text { excellent work. }\end{array}$ \\
\hline
\end{tabular}

[7]. It is important to note that the narrative below also highlights the background events that led to the professor experiencing anger, as well as the events that are related to altering his emotional state. The following is a suggested narrative prototype for technology-related anger:

The newly hired assistant professor is excited about his brand-new job at a well-respected university. The professor spends the entire summer preparing to teach an introduction to information systems course. To impress his students (and colleagues), he creates detailed and interactive PowerPoint slides, which include YouTube videos and interactive online quizzes. Finally, after months of planning, the first day of class arrives. The professor feels well-prepared. He also feels a bit more nervous than he had originally anticipated, given that he recently found out that one of his colleagues will be attending his first few lectures as well. The professor steps into the classroom and begins teaching. "Welcome class," the professor says, as he loads his PowerPoint slides onto the classroom computer. Immediately, the professor is irked because the computer has a noticeable lag to it. The professor stands there awkwardly as the PowerPoint slides take about a minute to load. "You can't trust technology, am I right?" the professor says to the class, jokingly. "But you are the technology professor!" one student shouts. Other students laugh at the student's comment, not the professor's comment. "It's the computer I swear!" the professor says in a negative tone.

The professor then notices that his colleague is closely watching his every move. The PowerPoint 
slides finally load, and the professor continues with his lecture. He pushes the play button on the first of many YouTube videos. The video fails to load. "Here we go again," another student says loudly, which is followed by laughter. Eventually, the professor makes it through his first lecture, with a few more technical hiccups. At the end of the lecture, he promises the students that he will call the IT help desk staff and report the issues, which should be resolved by the next class. Two days later, the professor nervously stands in front of the class for the second lecture and loads the PowerPoint slides. Again, there is a delay. One student says, "Again!? Wow! We are paying for this?!" The professor tells the class that it is the help desk staff's fault and rants about the dated computer and associated software. While doing so, he feels like his students and colleagues may have lost some respect for him.

\subsection{Technology-related envy}

Envy involves "an individual wanting what someone else has" [1, p. 229]. Envy also entails an individual feeling as though they have been cheated or deprived, often by comparing themself to others in an unfavorable way. The individual also tends to rationalize or deny that they are deprived. Lazarus [1] provides an example of envy through an individual comparing himself to a celebrity. The individual wishes he had more money like a celebrity and feels cheated by the system. The individual, at the same time, convinces himself that celebrities are unhappy even though they are wealthy, and he is better off by not having so much money. In this sense, the core relational theme for envy requires (1) wanting what someone else has, (2) unfavorable comparisons with others, and (3) denial.

In IS research, one of the most studied technostressors is called techno-insecurity [5]. Technoinsecurity involves situations when "users feel threatened about losing their jobs to other people who have a better understanding of technology" [4]. In this sense, an individual likely experiences envy when encountering a technology-related stressful situation associated with techno-insecurity.

Below is an example narrative of envy in the context of healthcare IT and nurses using healthcare IT for work. The example involves a nurse who graduated from nursing school approximately 20 years ago. The nurse does not have what she considers great technology skills. She finds it difficult to keep up with her colleagues who recently graduated from nursing school. Some are about her age, and some are much younger. To her, the recent graduates seem much more technologically competent than she is. She often finds herself in situations asking the recent graduates how to use the electronic healthcare record system's software.

In the example below, the nurse asks a fellow nurse, who graduated from nursing school two years ago, how to access a patient's electronic file through the hospital's recently updated software interface. In doing so, she wishes that she had the training and technology skills possessed by the recent graduates and compares herself negatively to her more techsavvy colleagues. However, she reasons that she is a more competent nurse because she has many years of experience in other areas. The following is a suggested narrative prototype for technology-related envy:

"Could you please help me find my patient's medication file?" a nurse asks her colleague. "I just can't seem to remember how to access it in the system. I know you recent nursing school graduates are very tech-savvy." Her colleague agrees to help and quickly shows her how to access the file. "Thank you!" the nurse says. "I am sorry for constantly asking you for help with technology." The nurse feels grateful to have technologically competent colleagues, but also wishes she had a better understanding of how the technology works. She attributes this to her colleagues having better education coming out of nursing school, saying that much of the emphasis in nursing school nowadays is training on how to use technology to care for patients. "Ijust wish I knew that technology was going to change how we care for patients, and wish I had more knowledge about how to do that. I feel like I am constantly missing something," she thinks. "But unlike the recent grads, I have 20 years of experience under my belt, which I feel the patients appreciate."

\subsection{Technology-related relief}

Relief is a positive emotional experience related to an unfavorable condition [15]. When feeling relief, an individual experiences a threat about a given situation, and when the threat does not happen or the threat subsides, they experience relief. Lazarus [1] provides an example of a doctor diagnosing a patient with a potentially life-threatening medical condition. The doctor decides to perform a biopsy on the patient. While waiting for the results, the patient is highly concerned. When the doctor eventually tells the patient that their condition is treatable, the patient feels relief. The core relational themes are therefore (1) an unfavorable threat and (2) experiencing the threat subsiding.

Consider the following narrative about technology-related relief. The example involves the same assistant professor in the example of technologyrelated anger. This time, the professor begins the 
second semester of his first year and is eager to get off to a great start. However, he knows that the classroom computers can be highly unreliable and has experienced problems with the IT support staff. This time he has been assured by the university IT support staff that the computers have been upgraded and are running smoothly. The following is a suggested narrative prototype for technology-related relief:

After a rocky first semester, during which he experienced several technical glitches while teaching, an assistant professor is eager for a fresh start. It is the second semester of his first year teaching. The IT help desk staff has assured all faculty that the classroom computers will run seamlessly. Over the winter holiday, because of issues with the computers freezing, the IT staff upgraded all the classroom computers with the latest software and are $100 \%$ confident that things will run smoothly this semester. The professor is not convinced. On the first day of class, he feels highly worried about the possibility of technical glitches. "Good morning!" he says, as he steps in front of his first class. He loads his PowerPoint files onto the computer, and notices that there is no lag. "So far so good," he thinks. "The true test will be if the first video plays." Sure enough, the video loads and plays as desired. The professor makes it through his first class and the rest of the semester with no technical issues.

\subsection{Technology-related hope}

Hope occurs when an individual "fears the worst but yearns for the better" [1, p. 241]. Hope is similar to relief: it is related to an undesirable or uncertain situation. Whereas relief is associated with a more immediate feeling related to the undesirable situation subsiding, hope is concerned with a desire for an unfavorable situation to subside in the future. That is, hope is related to an outcome that has not yet occurred and is therefore considered an "anticipatory emotion" [1]. Brok [16] discusses hope eloquently by underscoring the feeling of motivation related to hope: "hope gives us a reason for existence, a sense of, and anticipation for, the future, and a motivation to live out our ambitions and desires" (p. 219). The core relational themes of hope are therefore (1) an undesirable or uncertain situation, (2) a sense of the situation abating in the future, and (3) a motivation to keep going.

Below is a hypothetical narrative about technology-related hope. The example is given from the perspective of a nurse who is frustrated with her hospital's recent switch from paper documentation to electronic documentation through an electronic healthcare record system. The nurse is feeling insecure about her technical skills. She has also heard from her colleagues at another hospital that the system is complex. She mentions that while she knows there will be a difficult transition period when moving from paper to digital, she is hopeful that, in the future, patients will receive better care. The following is a suggested narrative prototype for technology-related hope:

"I've been a nurse for a long time and am used to the way I document patient information," the nurse said when her boss asked how she was feeling about the switch to electronic documentation. For the last 20 years, she has been a practicing registered nurse at the same hospital. Her hospital has just announced that they will officially be implementing an electronic healthcare record system and will transition to electronic-only documentation within the year. "This is going to involve some serious training. I've heard the system is hard to use," the nurse thinks. She and her colleagues are not too excited about the new technology. They have heard from several of their friends who work at other hospitals that electronic documentation is complicated and can take away oneon-one time from interacting with patients, potentially jeopardizing the nurse-patient relationship. "I just hope I can still interact with and care for my patients," the nurse says. "I've heard that the system is hard to use and that nurses spend more time entering information into the computer than actually caring for patients. I just hope it isn't a barrier to my patient care."

The nurse ultimately knows that patient data and patient care will be electronic in the future and can see the benefits as well. She therefore can see the longterm benefits which motivate her to keep going. "Ultimately I know this will be better for patient care in the long run. Patients can access their data, and nurses and doctors can quickly see detailed information about past visits. I am just feeling uneasy about the time it will take to get to that point, but I know we will get there."

\subsection{Technology-related happiness-joy}

Happiness is an emotion that most people think they can readily identify, and for that reason, happiness is often misunderstood [1]. For example, individuals may say they are happy for a variety of reasons - they received a promotion at work, they have a great romantic relationship, and so on. In doing so, individuals often misunderstand the essence of happiness and its relationship with joy. Researchers 
suggest that these feelings of happiness that humans experience should be compared to joy [1].

Happiness has been defined as a calming feeling of personal well-being [17], while joy has been defined in terms of events that individuals interpret as evidence that their life is going well [1]. The two concepts are frequently discussed together because it is often difficult to decipher what research subjects mean when they say they are happy. For example, a research subject could say she is happy about a recent positive life event, such as winning an award at work. Since, as defined here, happiness is about an overall positive feeling about one's life, and not about an event, the research subject may mistakenly describe herself as happy about winning the award but mean she is joyful. Overall, happiness is a long-term feeling of comfort and reassurance, and joy is a relatively short-term feeling, often lasting minutes, hours, or days. In this sense, the relational theme of happinessjoy involves (1) a temporal state, (2) general statements vs. specific events, and (3) a positive interpretation of well-being.

Below is an example of a hypothetical narrative involving the same registered nurse in section 6.4 who describes herself as happy with her hospital's electronic healthcare record system but is actually feeling joyful that she has mastered some of its features, which she perceived as complex. This may result in the researcher (or the nurse's superior) interpreting her statements as being happy with the technology. But if the researcher were to look a bit deeper at what she is saying, they would realize that the nurse is experiencing joy related to an event and is actually unhappy. This is because, when asked about her overall interpretation of the technology she uses for work, she still describes the technology as a barrier to patient-centered care and building relationships. The following is a suggested narrative prototype for technology-related happiness-joy:

A nurse was having trouble figuring out how to use her hospital's newly implemented healthcare IT. She always thought of herself as computer-savvy, but could not seem to grasp how to use several features of the technology. She therefore decided to take a class offered by his hospital's help desk support staff. Once the class ended, the nurse felt elated. "I'm happy that I've learned how to use the computer!' the nurse said when her boss asked how the class went. "I feel much more competent." However, the nurse and her colleagues, when asked how they feel about using the technology to deliver patient care, often used disparaging words. For example, the emergency room nurse regularly says "The technology is a barrier to building a one-on-one relationship with my patient. I spend more time looking at the computer than I do looking at my patient. This is unsettling and I'm not thrilled with the future of healthcare."

\subsection{Technology-related pride}

Pride has been defined specifically as "enhancing one's self or ego identity by taking credit for a valued object or achievement either our own or that of someone or group with whom we identify" [1, p. 250]. Like happiness, pride is a positive feeling of wellbeing. Pride also is linked to an event that elevates one's worth or social status. In this sense, the core relational themes are (1) a positive feeling, (2) a positive event, and (3) taking credit.

An obvious example is feeling pride about one's favorite sports team winning the big game. The individual did not necessarily accomplish anything, but often takes credit and feels proud about the team's success. Pride can also involve feeling positive about one's success as well, given that one's worth (or perceived worth) or social status (or perceived social status) is enhanced. Unfortunately, pride also has a dark side [18]. That is, one can have too much pride and may exhibit hubris. Here, we focus on the positive side of pride.

Below is a hypothetical example of technologyrelated pride. The example involves a professor who wants to offer a new class on data analytics and data visualization, but has heard that the software is a bit complicated to use; the professor therefore may be experiencing a techno-stressor called technocomplexity [4]. She also feels insecure about learning new software. The professor spends the summer learning the data visualization tool. In doing so, the professor feels proud of her accomplishments because she has not only become proficient with the software but has become the go-to colleague in her department and college for visualizing data. Her department chair and colleagues are highly impressed with her newfound skills, since they, too, have heard that the visualization tool is hard to use. The dean even recognizes her and her departmental colleagues in a meeting as an innovative professor and department, therefore elevating her status, and her department's status, within the college. The following is a suggested narrative prototype for technology-related pride:

A professor of information systems is becoming a bit tired of teaching the same classes each semester. She therefore decides to spend her summer break learning a popular data visualization tool so that she can offer a class on visualizing and analyzing data. "This is going to be a lot of work," she thinks. "I've heard this tool is highly complex, so I'm feeling quite 
overwhelmed. But overall I am excited!" the professor tells her department chair. She spends all summer reading several books and watching tutorials online about how to use the visualization tool. She eventually learns the tool and feels ready to offer the class. She teaches the class that fall. The course goes extremely well, and the students are highly satisfied. She receives high marks on her course evaluations. The professor tells her department chair that she is elated about learning the new technology and how well the class went. Her chair tells her that several colleagues have mentioned how impressed they are with her newfound skills, and with her initiative. Moreover, the chair says that the dean is going to recognize her as an outstanding and innovative teacher at the next college meeting.

\section{When to use the narrative approach to technostress and emotion}

As with any novel research approach, there may be a misunderstanding about when and how to use the approach. Below we discuss four fruitful avenues through which IS researchers may find a narrative approach useful: (1) when building rapport, (2) in mixed-methods research, (3) in focus groups, and (4) in survey research designs.

\subsection{Building rapport}

One common way to employ the use of narratives and vignettes in general is to develop a rapport with a research subject and to prompt discussion [19], especially around sensitive topics like emotion. The interviewer could have the interviewee read through one or more example vignettes, therefore allowing the interviewee to understand that they may feel like the individual(s) in the example. This could then prompt a meaningful discussion about emotion and technostress by comparing the example narratives to the interviewee's experiences. However, it should be noted that the goal of qualitative research involving interviews is often to have the subject reveal their truth using their own words [20, 21]. The researcher must therefore be cognizant of the wording used by the interviewee in case it matches that used in the example narrative.

\subsection{Mixed-methods research}

Over the last decade, there have been several calls for IS researchers to conduct mixed-methods studies in various contexts to provide a more meaningful understanding of reality [22, 23]. For example, emotion narratives could be used in conjunction with semi-structured interviews to elicit opinions by interviewees on certain situations. The researcher could, for example, conduct several interviews first, develop the emotion narratives, and ask interviewees in later stages of the investigation to comment on the narratives. The researcher could adapt the narratives using an iterative approach to data analysis [21], and, eventually, introduce to the literature a general thematic narrative for common situations. The researcher could also develop a quantitative model based on the more general narratives inspired by the interviews, and test the model using quantitative research methods such as structural equation modeling. In doing so, the researcher would take a more inductive approach building and testing a contextually driven quantitative research model [24].

\subsection{Focus groups}

Researchers may also consider using emotion narratives when conducting focus groups. For example, narratives could be read aloud in a group setting, and the researcher could ask the participants to comment on how they feel about each situation [19]. This may enable, for example, an individual in the focus group to speak out about their feelings, given that they might be represented in the example narrative [19]. Managers could also consider using narratives in this way to encourage employees in a group setting to discuss a potentially sensitive topic.

\subsection{Survey research}

IS researchers could use emotion narratives in quantitative or survey research designs [25]. As an example, the researcher could design several versions of an emotion narrative and randomly assign them different versions to survey respondents who would indicate how much the narrative relates to their experience on a 1 to 5 scale. The researcher could design the narratives to explore the relationship between a single techno-stressor and a single emotion, and design alternative narratives that swap out the techno-stressor and/or the emotion. For example, if the researcher chooses four potential techno-stressors and three emotions, there could be 12 potential narratives.

\section{Conclusion}

This paper advocates that identifying specific emotions is critical to understanding the essence of stress [1]. Unfortunately, in research on technostress, 
emotions have been overlooked or overgeneralized. This paper provides IS researchers with a means to uncover the emotional experiences of individuals undergoing technostress through the narrative approach. Using this approach, IS researchers can reveal the emotions that relate to specific technostressors, and therefore can better understand how techno-stressors materialized and why certain individual and organizational outcomes related to technostress occur. The paper also details how the narrative approach to technostress and emotion can be used in a variety of ways, such as building rapport with an informant or interviewee, as a part of mixedmethods research, in focus groups, and/or in survey research. We hope this paper helps to spotlight the importance of emotions in understanding the actions and reactions of human behavior in the context of stress and technology and encourages greater emphasis on emotions when studying technostress.

\section{References}

[1] Lazarus, R.S., Stress and emotion: A new synthesis. Springer, 2006.

[2] Baroudi, J.J. "The impact of role variables on IS personnel work attitudes and intentions," MIS Quarterly, 1985, pp. 341-356.

[3] Weiss, M. "Effects of work stress and social support on information systems managers," MIS Quarterly, 1983, pp. 29-43.

[4] Ragu-Nathan, T.S., Tarafdar, M., Ragu-Nathan, B.S. and $\mathrm{Tu}, \mathrm{Q}$., "The consequences of technostress for end users in organizations: Conceptual development and empirical validation," Information Systems Research, 2008, pp. 417-433.

[5] Tarafdar, M., Tu, Q., Ragu-Nathan, B.S. and RaguNathan, T.S., "The impact of technostress on role stress and productivity, "Journal of Management Information Systems, 2007, pp.301-328.

[6] Califf, C.B., Sarker, S., Sarker, S., and Fitzgerald, C., "The bright and dark sides of technostress: An empirical study of healthcare workers," Proceedings of the International Conference on Information Systems, 2015.

[7] Califf, C. B., Sarker, S., and Sarker, S., "The Bright and Dark Sides of Technostress: A Mixed-Methods Study Involving Healthcare IT," MIS Quarterly, 2020, pp. 809-856.

[8] Tarafdar, M., Cooper, C.L., \& Stich, J.F., "The technostress trifecta-techno eustress, techno distress and design: Theoretical directions and an agenda for research," Information Systems Journal, 2019, pp. 642.

[9] Lazarus, R.S., \& Lazarus, B.N., Passion and reason: Making sense of our emotions, Oxford University Press, 1994.
[10] Cooper, C. L., Cooper, C. P., Dewe, P. J., Dewe, P. J., O'Driscoll, M. P., \& O'Driscoll, M. P., Organizational stress: A review and critique of theory, research, and applications, Sage, 2001.

[11] Lazarus, R.S., and Folkman, S., Stress, appraisal, and coping, Springer, 1984.

[12] Hargrove, M.B., Nelson, D.L., and Cooper, C.L., Generating eustress by challenging employees: Helping people savor their work, Organizational Dynamics, 2013, pp. 61-69.

[13] LePine, J.A., LePine, M.A., \& Jackson, C. L., Challenge and hindrance stress: relationships with exhaustion, motivation to learn, and learning performance, Journal of applied psychology, 2004, pp. 883-891.

[14] Brod, C., Technostress: The human cost of the computer revolution. Addison-Wesley, 1984.

[15] Morita, T., Tsuneto, S., and Shima, Y., "Definition of sedation for symptom relief: a systematic literature review and a proposal of operational criteria." Journal of pain and symptom management, 2002, pp. 447-453.

[16] Brok, A.J., "Hope, Envy, Illusion, and Reality in Analytic Group Therapy: An Essay and a Vignette," Group, 2013, pp. 219-227.

[17] Diener, E., Horwitz, J., and Emmons, R.A., "Happiness of the very wealthy," Social indicators research, 1985, pp. 263-274.

[18] Gruber, J., Mauss, I.B., \& Tamir, M., “A dark side of happiness? How, when, and why happiness is not always good," Perspectives on psychological science, 2011, pp. 222-233.

[19] Barter, C. and Renold, E., "The use of vignettes in qualitative research," Social research update, 1999, pp.1-6.

[20] Myers, M.D., "Investigating information systems with ethnographic research," Communications of the Association for Information Systems, 1999.

[21] Sarker, S., Xiao, X., \& Beaulieu, T. "Guest editorial: Qualitative studies in information systems: A critical review and some guiding principles. MIS Quarterly, 2013, pp. iii-xviii.

[22] Venkatesh, V., Brown, S. A., and Bala, H., "Bridging the qualitative-quantitative divide: Guidelines for conducting mixed methods research in information systems. MIS Quarterly, 2013, pp. 21-54.

[23] Venkatesh, V., Brown, S. A., and Sullivan, Y. W., "Guidelines for conducting mixed-methods research: An extension and illustration," Journal of the Association for Information Systems, 2016.

[24] Hong, W., Chan, F. K., Thong, J. Y., Chasalow, L. C., and Dhillon, G., "A framework and guidelines for context-specific theorizing in information systems research." Information systems research, 2014, pp. $111-136$

[25] Alexander, C.S. and Becker, H.J., "The use of vignettes in survey research," Public opinion quarterly, 1978, pp.93-104. 